\title{
RANCANG BANGUN SISTEM INFORMASI DOKUMENTASI KEGIATAN SCIENCE TECHNO PARK BERBASIS WEB PADA PUSAT INOVASI LIPI
}

\author{
Karno $^{1}$, Tri Budi Setyaningsih ${ }^{2}$, Andis Priswantoro ${ }^{3}$ \\ ${ }^{1}$ Pusat Inovasi, Lembaga Ilmu Pengetahuan Indonesia \\ ${ }^{2}$ Pusat Inovasi, Lembaga Ilmu Pengetahuan Indonesia \\ ${ }^{3}$ Pusat Inovasi, Lembaga Ilmu Pengetahuan Indonesia \\ Email: ${ }^{1}$ karno@lipi.go.id, ${ }^{2}$ tribudi.setyaningsih@yahoo.com, ${ }^{3}$ andis.priswantoro@gmail.com
}

(Naskah masuk: 8 Agustus 2016, diterima untuk diterbitkan: 8 September 2016)

\begin{abstract}
Abstrak
Pusat Inovasi adalah satuan kerja di Lembaga Ilmu Pengetahuan yang mempunyai tugas untuk mengelola kegiatan Science Techno Park. Pengelolaan Science Techno Park di Pusat Inovasi pada umumnya memberikan penekanan pada pemberian layanan alih teknologi dari lembaga litbang maupun universitas kepada industri maupun perusahaan start up. Karena pentingnya proses layanan Science Techno Park tersebut diperlukannya sebuah sistem informasi dokumentasi dari kegiatan tersebut. Karena selama ini proses dokumentasi mengalami beberapa kesulitan yaitu sulitnya mendapatkan laporan, foto dan informasi lain dari kegiatan karena peneliti yang tersebar di masing-masing satuan kerja maupun lembaga litbang. Dengan adanya hambatan tersebut maka pengelola Science Techno Park mengalami kendala untuk mendapatkan informasi yang berupa laporan, foto maupun detail kegiatan dari peneliti. Oleh karena itu dalam penelitian ini bertujuan untuk merancang dan membagun sebuah sistem informasi dokumentasi kegiatan Science Techo Park berbasis web agar mempermudah pengelola untuk mendapatkan laporan maupun informasi lain dari kegiatan. Metode yang digunakan dalam pengembangan sistem adalah metode waterfall yang meliputi analisis kebutuhan, desain, koding, pengujian dan pemeliharaan. Sedangkan pada proses pengujian menggunakan metode blackbox dan perbandingan efisiensi waktu antara sistem manual dengan sistem berbasis web. Pada pengujian didapatkan hasil bahwa dengan metode blackbox sistem dapat berjalan sesuai modul yang direncanakan pada use case yaitu dengan melakukan inputan data ke masing-masing modul. Sedangkan pada pengujian efisiensi waktu diperoleh hasil bahwa sistem berbasis web lebih efisien karena memiliki waktu yang lebih cepat dibandingkan dengan sistem manual.
\end{abstract}

Kata Kunci: science techno park, dokumentasi, sistem informasi

\section{Abstract}

Center for innovation is the unit at the Indoensian Institute of Sciences which has the task to manage Science Techno Park. Management Science Techno Park in Center fo Innovation focused to provide the service of techbology transfer from research institutions and universisty to industry or start up company. Management process of science techno park is very important, so it needs the information system for documentation. Because during the documentation process encountered some difficulties, The problems in the documentation process of $S T P$ is difficult to obtain documents, photos, and the progress of the researcher because researchers scattered in their respective work units or $R \& D$ institutions. Given these constraints, the manager of Science Techno Park have problems to get information in the form of reports, photos and details of activities of researchers. Therefore, the purpose of this research is to design and build their information system documentation of Science Techno Park to facilitate the management to obtain reports and other information of activities. The method used in the development of the system is the waterfall method which includes requirements analysis, design, coding, testing and maintenance. While in the testing process using blackbox and time efficiency comparison between a manual system with a web-based system.On blackbox testing showed that the system will be implemented as planned modules in use case. And on the test result that the time efficiency of web-based system is more efficient because it has a faster time than the manual system.

Keywords: science techno park, documentation, information system

\section{PENDAHULUAN}

Pusat Pusat Inovasi salah satu satuan kerja di Lembaga Ilmu Pengetahuan Indonesia yang mempunyai tugas dan fungsi yaitu melakukan kegiatan kerjasama yang dilakukan oleh berbagai pusat penelitian dan UPT LIPI dengan pihak di luar terutama dengan industri, dalam upaya pemanfaatan hasil penelitian dan melakukan kajian kemungkinan perlindungan kekayaan intelektual hasil litbang LIPI serta melaksanakan proses untuk mendapatkan perlindungan tersebut. Sesuai dengan tugas dan fungsi tersebut pada tahun 2015 dan 2016 Pusat Inovasi LIPI ditunjuk untuk mengelola program Science Techno Park yang merupakan salah satu program nawa cita. Science Techno Park adalah 
kawasan yang diperuntukan bagi penelitian dan pengembangan sains dan teknologi berdasarkan pada kepentingan bisnis. Pembangunan Techo Park diarahkan berfungsi sebagai sebagai pusat penerapan teknologi diberbagai bidang yang telah dikaji oleh lembaga penelitian, swasta dan universitas untuk diterapkan dalam skala ekonomi.

Mengingat begitu pentingnya program Science Techno Park dilingkungan LIPI maupun nasional maka diperlukan mekanisme dan tata kelola dokumentasi kegiatan agar kegiatan berjalan dengan baik. Tata kelola dokumentasi ini diperlukan agar monitoring pencapaian kegaiatan dapat dilakukan secara tepat sehingga setiap kegiatan pada program Science Techno Park berjalan sesuai target.

Permasalahan yang dihadapai pada kegiatan dokumentasi dan monitoring pada kegiatan Science Techno Park adalah peneliti yang tersebar dimasingmasing unit kerja yang letak antar unit kerja berjauhan sehingga menyebabkan waktu dan biaya untuk melakukan koordinasi dokumentasi lebih lama dan mahal. Selain itu permasalahan lain yang muncul adalah sulitnya mengontrol dokumentasi kegiatan penelitian semua peneliti.

Dari permasalahan-permasalahan tersebut Pusat Inovasi LIPI sebagai pengelola program perlu membuat dan mengimplementasikan sebuah sistem informasi dokumentasi kegiatan Science Techno Park untuk mendukung dalam melakukan dokumentasi dan monitoring kegiatan penelitian. Dengan dibangun dan diimplementasikan sistem ini nantinya dapat meningkatkan efisiensi pada proses dokumentasi dan monitoring kegiatan penelitian pada program Science Techno Park.

\section{METODE}

Metode pengambilan data terkait dengan kebutuhan-kebutuhan dan permasalahan sistem dilakukan dengan metode observasi, wawancara dan studi pustaka. Pada metode obervasi yaitu dengan pengamatan langsung mengenai proses kegiatan dokumentasi. Untuk metode wawancara yaitu dengan melakukan diskusi dengan pihakpihak yang berkaitan langsung. Sedangkan untuk studi pustaka yaitu dengan mempelajari teori-teori pengembangan sistem melalui buku, jurnal, dan prosiding. Dari pengambilan data dan analisa permasalahan dibuat analisa kebutuhan sistem yang akan dibangun.

Sedangkan untuk pengembangan sistem menggunakan metode waterfall yang meliputi analisis kebutuhan, desain, implementasi, pengujian dan pemeliharaan (Pressman, 2009). Untuk pengujian melalui 2 cara yaitu pengujian software melalui metode blackbox dan pengujian waktu untuk pemrosesan data dan pemyampaian informasi. Pada metode pengujian blackbox yaitu dengan melakukan uji coba ke semua menu atau fungsi software dengan melakukan inputan kedalam sistem (Kadir, 2009). Dan untuk metode pengujian waktu yaitu dengan mencatat dan membandingkan waktu pemrosesan data dan penyampaian informasi pada sistem manual dan sistem yang dikembangkan.

\section{HASIL DAN PEMBAHASAN}

Pada bagian bab ini dibahas mengenai tahapantahapan pembangunan sistem menggunakan metode waterfall yaitu analisa kebutuhan, perancangan sistem, implementasi sistem, dan pengujian sistem.

\subsection{Analisa Permasalahan}

Dengan melakukan observasi dan wawancara diperoleh informasi mengenai permasalahanpermasalahan yang terjadi pada proses dokumentasi kegiatan Science Techno Park. Adapun analisa pohon permasalahan ditunjukan gambar 1 sebagai berikut :

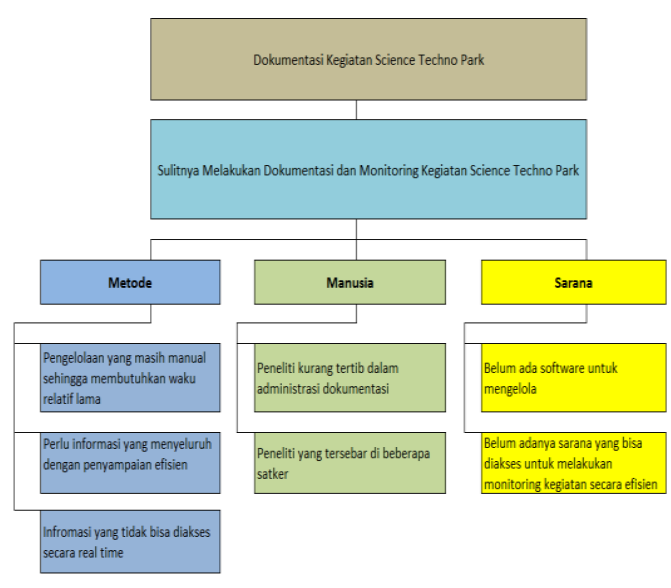

Gambar 1. Pohon Permasalahan

Analisa permasalahan ini diperlukan untuk menyusun requirement dari sistem. Pada saat melakukan analisa dalam pengumpulan dengan wawancara kepada pegawai yang bersangkutan dan menganalisa kebutuhan dokumen yang diperlukan untuk dokumentasi. Analisa permasalahan ini bertujuan agar sistem yang dibangun sesuai dengan sistem yang dibutuhkan oleh pengelola Science Techno Park dalam melakukan dokumentasi dan monitoring kegiatan.

\subsection{Perancangan Sistem}

Pada perancangan sistem ini perlu dilakukan agar sistem yang dibangun sesuai dengan kebutuhan user. Perancangan sistem dianalisa dari requirement sistem kemudian digambarkan dalam diagram. Pada tahap perancangan sistem ini menggambarkan alur dari sistem yang akan dibangun. Perancangan sistem ini dimodelkan menggunakan bahasa pemodelan sistem yaitu UML (Unified Modelling Language) yang terdiri dari usecase diagrams, sequence diagrams, activity diagrams dan relasi tabel. $U M L$ adalah bahasa standar untuk memvisualisasikan, spesifikasi, membangun, dan mendokumentasikan 
sistem perangkat lunak secara detail (Dennis et al, 2010).

\subsubsection{Use Case Diagram}

Use case diagram adalah diagram yang menggambarkan fungsional sistem (Gomaa, 2011). Pada use case diagram yang ditunjukan gambar 2 menggambarkan fungsional dari sistem yang akan dibangun. Dimana terdapat 3 aktor yaitu pengunjung, admin dan peneliti. Dimana hak akses ketiga aktor tersebut berbeda-beda sesuai dengan use case pada sistem atau boundary.

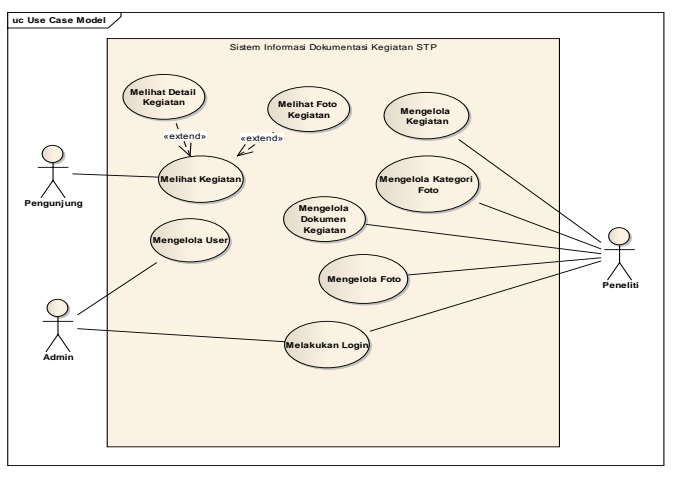

Gambar 2. Use Case Diagrams

\subsubsection{Sequence Diagrams}

Pada halaman login yang ditunjukan pada gambar 3 merupakan proses mengakses modul sistem sesuai dengan level actor yang terdeteksi oleh halaman login yaitu dengan memasukan username dan password. Pada sequence diagram melakukan login terdapat actor, boundary, entity, process, dan method.

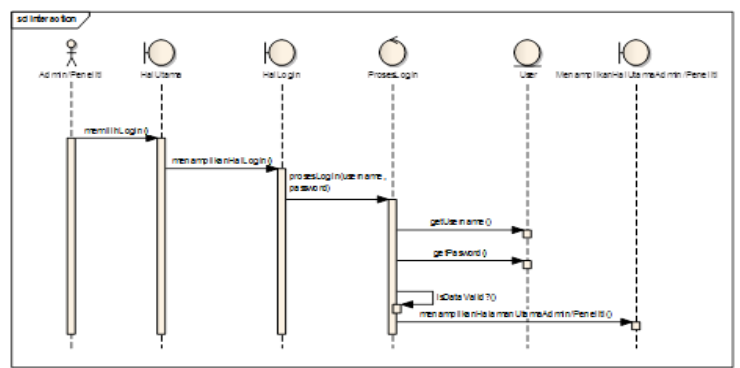

Gambar 3. Sequence Diagrams Melakukan Login

Selanjutnya adalah sequence diagram mengelola dokumen yang ditunjukan pada gambar 4 terdapat dua boundary, satu process dan dua entity yang masing-masing hubungan antara boundary, process dan entity ditunjukan dengan message dan method.

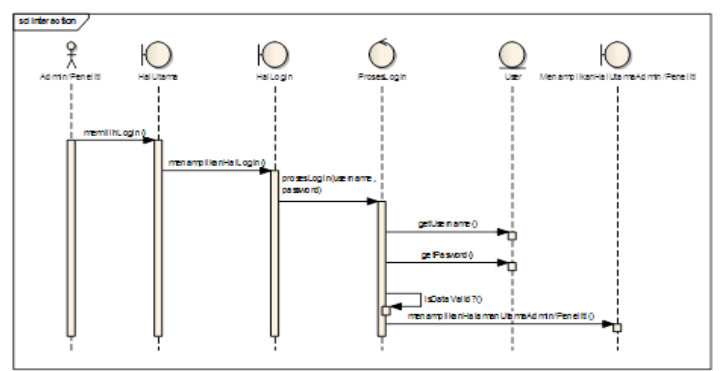

Gambar 4. Sequence Diagrams Mengelola Dokumen
Pada gambar 5 adalah sequence diagram mengelola kegiatan. Pada sequence diagram mengelola kegiatan ditunjukan dengan aliran process dan method dengan actor adalah peneliti. Berikut ini adalah tampilan sequence diagrams mengelola kegiatan.

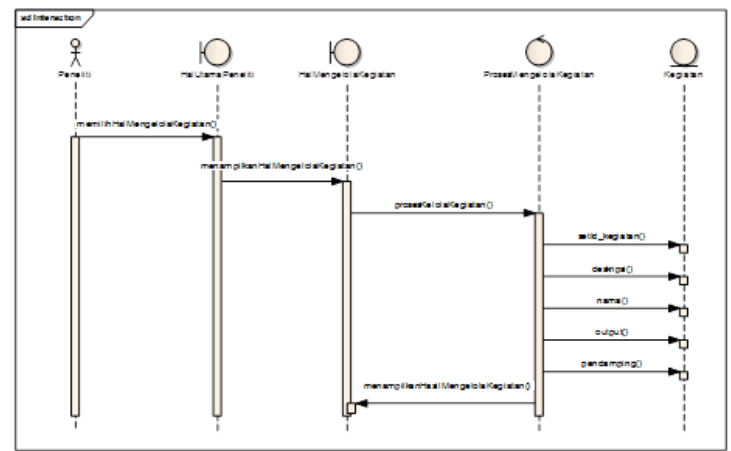

Gambar 4. Sequence Diagrams Mengelola Kegiatan

\subsubsection{Activity Diagrams}

Activity diagrams menggambarkan hubungan aktivitas antara sistem dengan aktor (Gomaa, 2011). Pada activity diagram mengelola dokumen yang ditunjukan gambar 5 dimulai start kemudian aktor peneliti memilih mengelola dokumen, sistem menampilkan mengelola dokumen, aktor kemudian melakukan pengelolaan dokumen, ketika data tidak valid sistem menampilkan pesan gagal dan ketika data valid sistem menampilkan hasil dari pengelolaan dokumen.

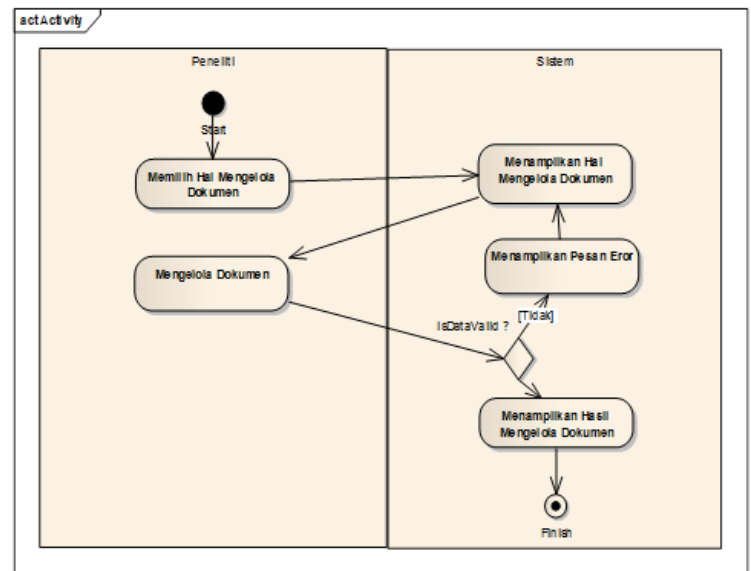

Gambar 5. Activity Diagrams Mengelola Dokumen

Pada gambar 6 dibawah ini adalah activity diagram mengelola kegiatan. Adapun urutannya adalah actor memilih hal mengelola kegiatan, sistem menampilkan halaman, kemudian actor mengelola kegiatan dan ketika data tidak muncul pesan gagal sedang ketika data valid menampilkan hasil kelola kegiatan. 


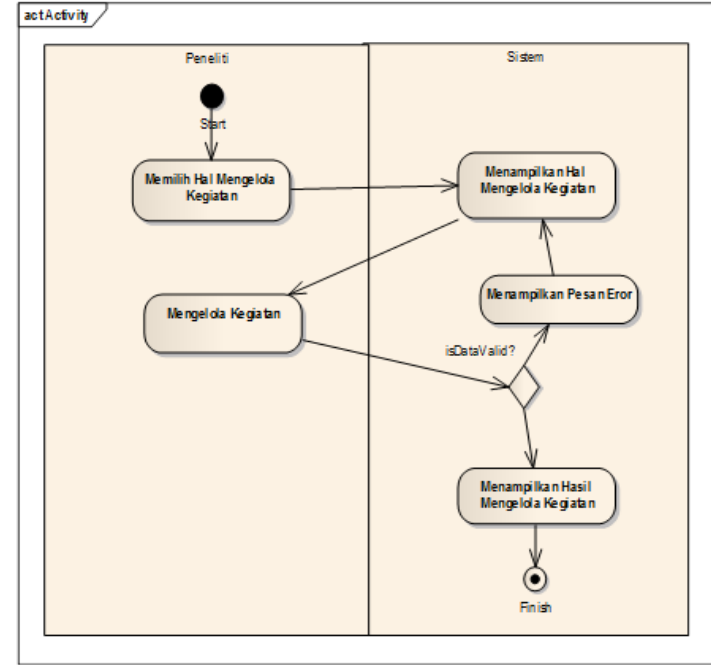

Gambar 6. Activity Diagrams Mengelola Dokumen

\subsection{Relasi Tabel}

Pada relasi table yang ditunjukan gambar 7 terdapat lima tabel antara lain user, kegiatan, dokumen, gallery, dan album. Pada relasi tabel ini tabel user dan kegiatan dihubungkan oleh id_user, tabel kegiatan dan dokumen dihubungkan oleh id_kegiatan, tabel gallery dan album dihubungkan oleh id_album, dan tabel album kegiatan dihubungkan oleh id_kegiatan. Adapun relasi tabel sistem informasi dokumentasi kegiatan STP adalah sebagai berikut:

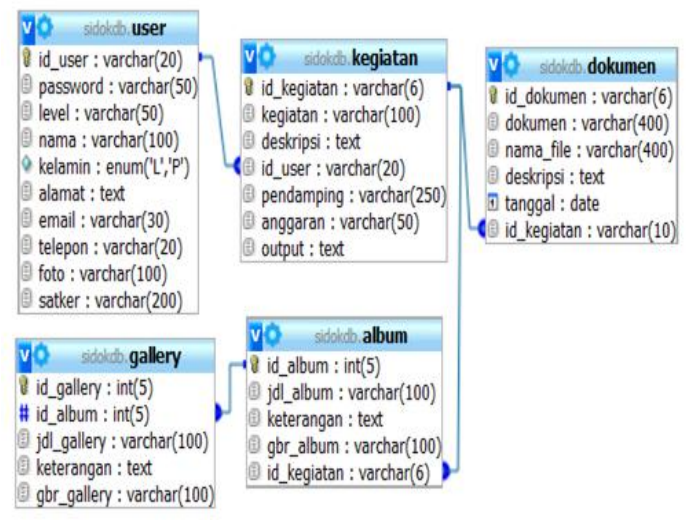

Gambar 7. Relasi Tabel

\subsection{Implementasi Sistem}

Setelah tahapan perancangan selesai proses selanjutnya adalah proses implementasi. Pada proses implementasi sistem ini, menggunakan bahasa pemrograman $P H P$ untuk membuat fungsi-fungsi didalamnya. Tampilan pada halaman sistem menggunakan HTML dan Bootstrap, sedangkan untuk database menggunakan $M y S Q L$. Penggunaan bootstrap berfungsi untuk mengkonversi tampilan agar responsive sehingga ketika dibuka menggunakan perangkat smartphone sistem menyesuaikan tampilan smartphone (Alatas, 2015). Berikut ini tampilan implementasi sistem informasi:

\subsubsection{Penggunaan HTML dan Bootstrap}

Pada gambar 8 menunjukan pemanggilan kode bootstrap pada baris ke 17 pada kode, berfungsi untuk menggunakan fungsi-fungsi pada bootstrap seperti responsive web, tanggal, dan form. Sedangkan tag-tag html ditunjukkan dari baris 13 sampai 43 pada baris program.

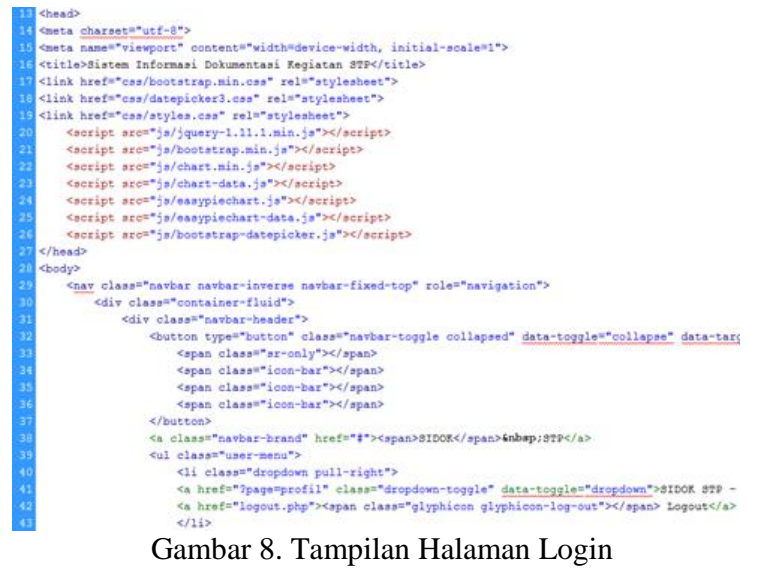

\subsubsection{Tampilan Halaman Mengelola User}

Pada halaman mengelola user seperti ditunjukan gambar 9 berfungsi untuk melakukan pengelolaan user sesuai dengan hak akses. Ada 2 tipe user yang dibuat yaitu admin dan peneliti, dimana admin mempunyai hak akses untuk mengelola user sedangkan peneliti mempunyai hak akses mengelola dokumen, kegiatan, foto, kategori foto dan mengedit profil.

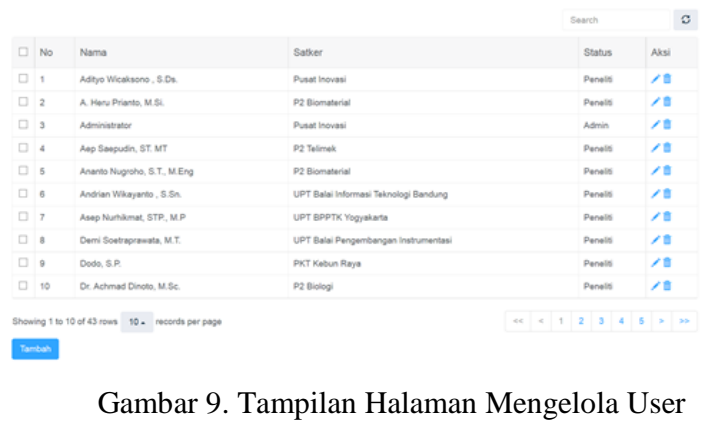

\subsubsection{Tampilan Halaman Mengelola Kegiatan}

Halaman mengelola kegiatan yang ditunjukan pada gambar 10 berfungsi untuk mengelola kegiatan Science Techno Park . Pada halaman ini terdapat informasi detail mengenai kegiatan meliputi judul kegiatan, deskripsi, peneliti, tim pembantu, anggaran, dan output dari kegiatan.

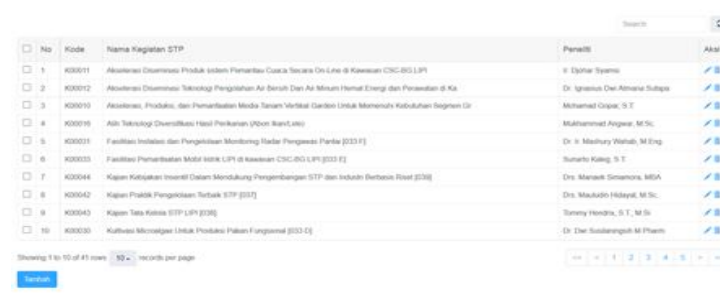

Gambar 10. Tampilan Halaman Mengelola Kegiatan 


\subsubsection{Tampilan Halaman Mengelola Dokumen}

Tampilan mengelola dokumen yang ditunjukan pada gambar 11 berfungsi untuk menampilkan dokumen-dokumen yang telah diupload peneliti ke dalam sistem. Adapun tampilan halaman mengelola dokumen adalah sebagai berikut:

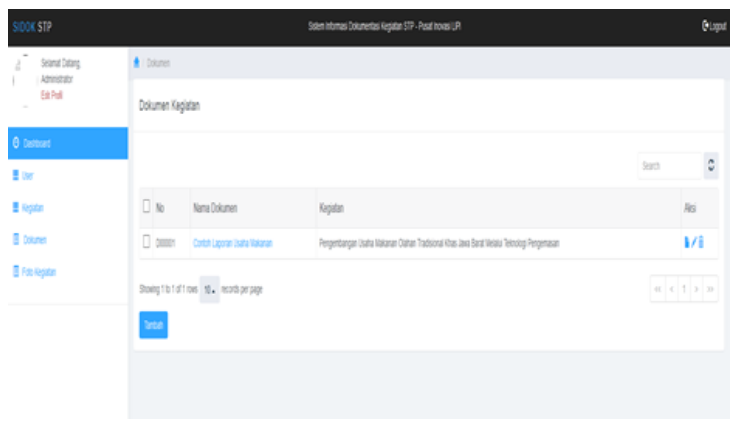

Gambar 11. Tampilan Halaman Mengelola Dokumen

\subsubsection{Tampilan Halaman Foto Kegiatan}

Pada halaman ini yang ditunjukan pada gambar 12 berfungsi untuk mengelola foto-foto kegiatan. Peneliti mengupload foto-foto kegiatan kedalam sistem. Pada halaman ini juga terdapat fasilitas pencarian foto kegiatan. Adapun tampilan halaman foto kegiatan adalah sebagai berikut :

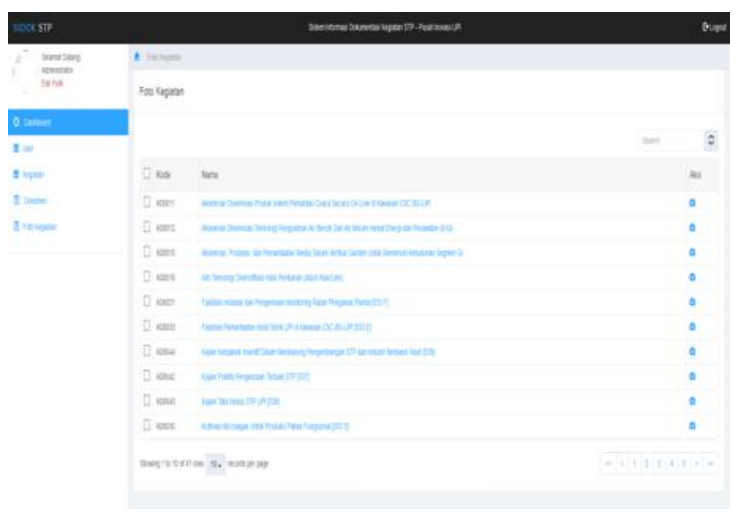

Gambar 12. Tampilan Halaman Foto Kegiatan

\subsection{Pengujian Sistem}

Setelah dilakukan implementasi pengkodean menggunakan bahasa PHP dan database MySQL tahap selanjutnya adalah proses pengujian sistem. Pada pengujian sistem menggunakan 2 cara pengujian yaitu menggunakan metode blackbox dan metode perbandingan waktu komputasi. Pada pengujian menggunakan metode blackbox yaitu dengan menguji setiap modul. Metode ini digunakan untuk mengetahui apakah perangkat lunak berfungsi dengan baik sesuai dengan fungsinya. Pengujian ini dilakukan dengan melakukan input kedalam sistem. Adapun hal-hal yang akan diujikan ditunjukan pada tabel 1 adalah sebagai berikut:

\begin{tabular}{|c|c|c|}
\hline Modul & Aksi & $\begin{array}{c}\text { Kesimpula } \\
n\end{array}$ \\
\hline Login & Melakukan login & Berhasil \\
\hline Kegiatan & $\begin{array}{l}\text { Tambah, edit, } \\
\text { hapus, dan cetak }\end{array}$ & Berhasil \\
\hline Foto Kegiatan & $\begin{array}{l}\text { Tambah, edit, } \\
\text { hapus, dan cetak }\end{array}$ & Berhasil \\
\hline Kategori Foto & $\begin{array}{l}\text { Tambah, edit, } \\
\text { hapus, dan cetak }\end{array}$ & Berhasil \\
\hline User & $\begin{array}{l}\text { Memilih } \\
\text { berdasarkan } \\
\text { tanggal }\end{array}$ & Berhasil \\
\hline $\begin{array}{l}\text { Detail } \\
\text { Kegiatan }\end{array}$ & $\begin{array}{l}\text { Tambah, edit, } \\
\text { hapus, dan cetak }\end{array}$ & Berhasil \\
\hline Profil & $\begin{array}{l}\text { Tambah, edit, } \\
\text { hapus, dan cetak }\end{array}$ & Berhasil \\
\hline Logout & $\begin{array}{l}\text { Tambah, edit, } \\
\text { hapus, dan cetak }\end{array}$ & Berhasil \\
\hline
\end{tabular}

Pada pengujian yang kedua yaitu pengujian dengan membandingkan waktu antara sistem manual dan sistem yang dibangun dalam penyampaian informasi. Nilai-nilai yang dihasilkan dengan pengamatan langsung terhadap sistem yang lama dengan sistem yang baru sehingga diperoleh perkiraan atau rata-rata nilai. Adapun nilai-nilai yang dihasilkan dari pengujian waktu komputasi ditunjukan pada tabel 2 sebagai berikut:

Tabel 2. Pengujian Penyampaian Informasi

\begin{tabular}{lccc}
\hline \multicolumn{1}{c}{ Modul } & & $\begin{array}{c}\text { Penyampaian Informasi } \\
\text { (Detik) }\end{array}$ \\
& & Manual & Sistem \\
\hline $\begin{array}{l}\text { Pencarian } \\
\begin{array}{l}\text { Kegiatan } \\
\text { Pencairan }\end{array}\end{array}$ & Detail & 230 & 27 \\
$\begin{array}{l}\text { Kegiatan } \\
\begin{array}{l}\text { Pencarian } \\
\text { Kegiatan }\end{array}\end{array}$ & Doto & 340 & 41 \\
\hline
\end{tabular}

\section{KESIMPULAN}

Dari hasil pengujian menggunakan metode blackbox terbukti bahwa semua modul pada sistem yang dibangun berjalan dengan baik sesuai dengan perancangan pada use case diagram. Sedangkan untuk pengujian dengan pencatatan waktu penyampaian informasi. Sistem ini memiliki waktu yang lebih baik dibandingkan dengan sistem manual sehingga penggunaan sistem informasi terbukti lebih efisien dibandingkan sistem manual.

\section{SARAN}

Untuk mempermudah dalam akses, sistem informasi dapat dikembangkan dalam modul berbasis android dengan menggunakan database yang sudah ada di sistem berbasis web. Selain itu agar sistem dapat berjalan perlu dilakukan sosialisasi kepada para pihak yang menggunakan sistem informasi serta komitmen dari seluruh 
peneliti untuk aktif dalam penggunaan sistem agar dokumentasi kegiatan berjalan dengan baik.

\section{UCAPAN TERIMA KASIH}

Penulis mengucapkan terima kasih kepada seluruh pegawai Pusat Inovasi LIPI atas kesediaan waktu dalam diskusi mengenai kebutuhan sistem yang dibangun sehingga sistem ini dapat dibangun sesuai dengan kebutuhan.

\section{REFERENSI}

Alatas, Husein. 2015. Proyek Membangun Responsive Web Design dengan Bootstrap 3 dan 4. Yogyakarta: Lokomedia

Brookshear, J.Glenn. 2003. Computer Science : an Overview. Jakarta : Erlangga

Dennis, Alan, Barbara Heley Wixcom and Roberta M. Roth. 2010. Systems Analysis and Design with UML $3^{\text {rd }}$ Edition. New York: John Wiley and Sons

Dharma, Akhmad. 2013. Trik Mudah Menguasai OOP dengan PHP. Yogyakarta: Lokomedia

Gomaa, Hassan. 2011.

SoftwareModelingandDesign:UML, Use Cases, Patterns, and Software Architectures, New York : Cambridge University Press.

Kadir, Abdul. 2009. Pengenalan Sistem Informasi. Yogyakarta: Andi.

Kristanto, Andi. 2008. Perancangan Sistem Informasi dan Aplikasinya. Yogyakarta : Gava Media

Kurniawan, Wahyu. 2015. Membuat Sistem Monitoring Pelanggaran Siswa Berbasis Web dan Android. Yogyakarta:Lokomedia.

Kusrini. 2006. Strategi Perancangan dan Pengelolaan Basis Data, Yogyakarta: Andi.

Simamora, Manaek. 2015. Laporan Kegiatan Semester I Pengembangan Science and Technology Park CSC-BG LIPI. Bogor : Pusat Inovasi Lembaga Ilmu Pengetahuan Indonesia

Pressman, Roger S. 2009. Software Engineering: A Practitioner's Approach. New Yok: McGraw-Hill Science

Sutarman. 2009. Pengantar Teknologi Informasi. Yogyakarta : PT. Bentang Pustaka 